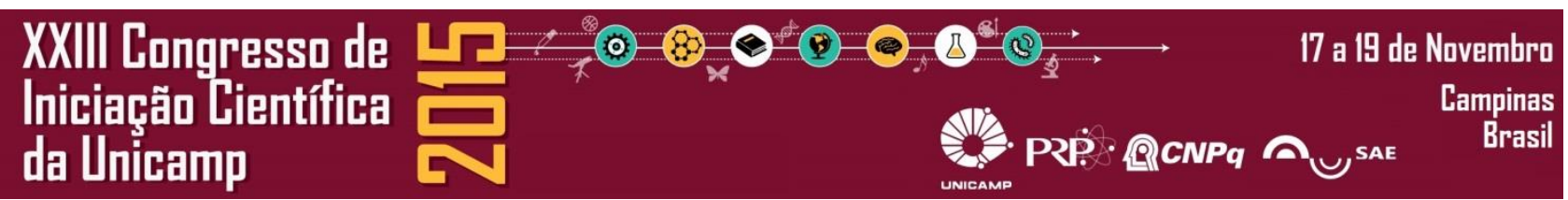

\title{
Estudo da partição da Bromelina em Sistema Bifásico Aquoso não Convencional como Método para sua Purificação de Resíduos Agroindustriais
}

\begin{abstract}
Resumo
Fernanda F. Fernandes (IC)

Na pesquisa objetivou-se estudar a eficiência da purificação da bromelina nos sistemas de PEG4000 e sulfato de amônio à diferentes concentrações e temperaturas. $O$ estudo do sistema bifásico foi baseado na construção de gráficos de Pareto e superfícies de contorno construídos no software Statistica 8.0 a partir de um planejamento fatorial. Palavras Chave: Bromelina, Purificação, Sistema Bifásico
\end{abstract}

\section{Introdução}

A bromelina é um extrato bruto e aquoso que envolve 0 conjunto de todas as proteases advindas dos membros pertencentes à família Bromeliaceae, a qual incluem o abacaxi e o curauá (Ananas erectifolius L.B. Smith). Dentre os estudos envolvendo a bromelina, podem-se citar como principais atividades medicinais, antiinflamatória, antitrombótica, antitumoral, atividade fibrinolítica (Maurer, 2001); agregação plaquetária (Heinicke e Wal et al., 1972), aumento da capacidade cardiorrespiratória, minimizando e prevenindo a severidade de casos de angina e isquemia (Bhattacharyya, 2008), e por fim, acelerar o processo de cicatrização, diminuindo as chances de infecção. Apoiado na sua importância, fez-se necessário a elaboração de processo de separação e purificação que promovesse 0 isolamento da bromelina no extrato do abacaxi. Para isso, elaborou-se um estudo em pequena escala para analisar a viabilidade do procedimento em larga escala.

\section{Resultados e Discussão}

Para o estudo do sistema elaborou-se um planejamento fatorial tornando possível o estudo do comportamento da bromelina nas diversas situações de concentração, temperatura e diluição do extrato. A partir dos gráficos construídos com a ferramenta Statisitica 8.0, podemos estudar os efeitos do fator de purificação, do rendimento e do coeficiente de partição no sistema PEG/Sulfato de Amônio.

Assim, pode-se constatar que quando o extrato é mantido à $25^{\circ} \mathrm{C}$, nenhum fator apresentou efeito significativo com relação ao fator de purificação, enquanto que para o rendimento da extração a diluição do extrato foi significativa. Porém, quando analisados os gráficos com o extrato mantido à 5 ${ }^{\circ} \mathrm{C}$, constatou-se que a diluição do extrato teve efeito significativo tanto para 0 fator de purificação, quanto para o rendimento da extração.

Por fim constatou-se que para os sistemas realizados com extrato mantido à $25^{\circ} \mathrm{C}$, apresenta-se como condição especifica para o fator de purificação ser ótimo concentração intermediária de PEG, baixa de Sulfato de Amônio e diluição intermediária de extrato. Já para que o rendimento tenha sua região de ótimo, concentração baixa de PEG e intermediária de Sulfato de Amônio e diluição baixa de extrato. Para os sistemas com extrato mantido à $5{ }^{\circ} \mathrm{C}$, apresenta-se como condição específica para 0 fator de purificação ser ótimo concentração baixa de PEG, intermediária de Sulfato de Amônio e diluição baixa de extrato. Já para que o rendimento tenha sua região de ótimo, concentrações baixas de PEG e Sulfato de Amônio e diluição intermediária de extrato. (Coelho et al., 2012).

\section{Conclusões}

Ao final dos resultados, apesar dos erros associados a todos os experimentos, esses não influenciaram muito no resultado do conjunto, já que foi um erro sistêmico, dessa forma, os resultados condizem com o esperado, uma vez que espera-se que quanto maior a concentração do extrato, mais proteínas este apresente, aumentando o rendimento da partição da bromelina.

\section{Agradecimentos}

O presente estudo é um trabalho de cooperação interinstitucional desenvolvido juntamente com o Prof. Dr. Elias Basile Tambourgi, da Faculdade de Engenharia Química da Universidade Estadual de Campinas e a Profa ${ }^{\text {a }}$ Dra . Priscila Gava Mazzola, da Faculdade de Ciências Médicas da Universidade Estadual de Campinas, fomentado pelo $\mathrm{PIBIC/CNPq}$.

\footnotetext{
BHATTACHARYYA, B. K. Bromelain: an overview. Natural Product Radiance, v. 7, p. 359-363, 2008.

COELHO, D. F., Purificação de Bromelina dos Resíduos de Abacaxi (Ananas comosus L. Merril) por Precipitação integrada a Sistema Bifásico Aquoso (PEG/Sulfato de Amônio) não Convencional, 2012. Tese de Mestrado, Faculdade de Engenharia Química, Universidade de Campinas - UNICAMP, Campinas, SP. MAURER, H. R. Bromelain: biochemistry, pharmacology and medical use. Cellular and Molecular Life Sciences, v. 58, n. 9, p. 1234-1245, 2001. ISSN 1420-682X.
} 